\title{
A Case of Myeloid Sarcoma Mimicking Otomastoiditis with Retroauricular Abscess
}

\author{
Da Jung Jung, MD, Hyun Ju Lee, MD, Ji Hye Kwak, MD and Kyu-Yup Lee, MD \\ Department of Otorhinolaryngology-Head and Neck Surgery, School of Medicine, \\ Kyungpook National University Hospital, Daegu, Korea
}

\begin{abstract}
- ABSTRACT -
Acute myelogenous leukemia (AML) is a type of cancer that typically involves intramedullary proliferation of myeloid precursor cells. Extramedullary manifestations of AML are exceedingly rare. They include myeloid sarcoma (chloroma), a disease in which extramedullary leukemia cells form a tumorous mass. Herein, we report a case of facial nerve paralysis that was caused by a myeloid sarcoma in the temporal bone. In this case, our preferred early differential diagnosis was otomastoiditis with retroauricular abscess; thus, the patient was scheduled for operative debridement and mastoidectomy. Further evaluation of the patient's symptoms confirmed a diagnosis ofmyeloid sarcoma, thus obviating the need for any surgical interventions and instead requiring chemotherapy followed by radiotherapy. (J Clinical Otolaryngol 2019;30:77-82)
\end{abstract}

KEY WORDS : Myeloid sarcoma $\cdot$ Temporal bone $\cdot$ Facial nerve paralysis $\cdot$ Chloroma.

\section{Introduction}

Myeloid sarcoma is a rare malignant condition that is defined by an extramedullary collection of immature myeloid cells. It occurs in $3 \%$ to $8 \%$ of acute myeloid leukemia (AML) patients and occur in any part of the body. Its most common sites are the periosteum, bones, soft tissues, skin, and lymph nodes. ${ }^{2)}$ Approximately $16 \%$ of myeloid sarcomas occur in the head and neck ; nevertheless, reports of myeloid sarcomas in the temporal bone are few. ${ }^{1,3)}$

Typically, the clinical presentation of myeloid sarcoma is secondary to the mass effect in regions exhibiting non-specific symptoms such as ear-fullness and otalgia. When associated with the temporal bone, my-

논문접수일 : 2018년 9월 13일

논문수정일 : 2019년 4월 30일

심사완료일 : 2019년 5월 30일

교신저자 : 이규엽, 41944 대구광역시 중구 동덕로 130

경북대학교 의과대학 경북대학교병원

이비인후-두경부외과학교실

전화 : (053) 420-5785·전송 : (053) 423-4524

E-mail:kylee@knu.ac.kr eloid sarcoma can cause otalgia, conductive hearing loss, bone destruction in nearby tissue, and retroauricular swelling leading to otomastoiditis. ${ }^{4)}$ There is no established treatment protocol for myeloid sarcoma; however, early and aggressive induction of chemotherapy followed by radiotherapy offers the best survival outcome. Long-term prognosis remains dismal; therefore, prompt recognition and timely treatment of myeloid sarcoma are critical. ${ }^{5,6)}$ Herein, we describe a rare otologic case of relapsed AML presenting as myeloid sarcoma of the temporal bone.

\section{Case Report}

A 22-year-old man with a history of AML (subtype M4 with the $8: 21$ translocation) presented with ear fullness, swelling of the retroauricular area, and sudden onset of right-sided facial paralysis 2 days earlier. He had previously received induction chemotherapy and 3 cycles of consolidation chemotherapy. After achieving complete remission 5 months before presentation, he had undergone peripheral blood stem cell 
transplantion. Additionally, after the second cycle of chemotherapy, he had been treated with antibiotics for otitis media of the left ear, and ear dressing had been applied. Physical examination revealed facial nerve palsy on the right side of his face (House-Brackmann grade 3/6). Significant narrowing of the right external auditory canal that obscured the eardrum and purulent otorrhea were observed via otoscopy (Fig. 1A). The findings for the left external auditory canal and tympanic membrane were non-specific (Fig. 1B). Subse- quent computed tomography (CT) revealed opacification, although the structures in the mastoid antrum and the mastoid air cells were relatively intact on both sides (Fig. 2A). However the right cortical bone near the auditory canal was partially eroded. In addition, a welldemarcated, homogenously enhanced dense soft-tissue mass was observed in the right postauricular area (Fig. 2B). Magnetic resonance imaging (MRI) confirmed the presence of a well-defined mass in the retro auricular area that extended to the external auditory
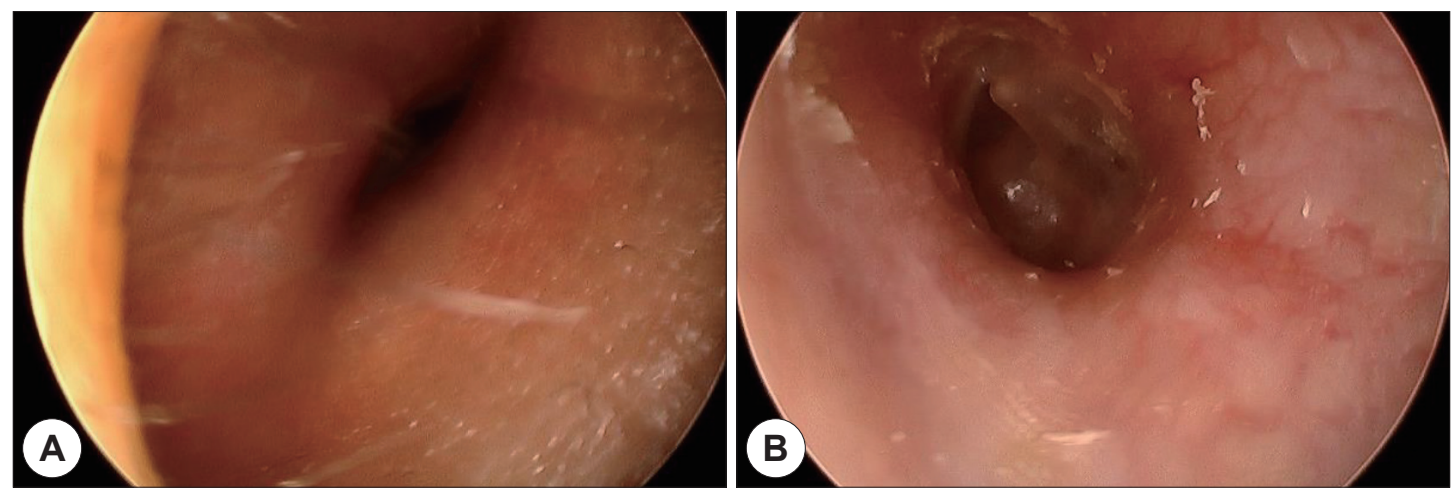

Fig. 1. Otoscope finding of tympanic membrane. A : Otoscopy shows that the right external auditory canal is very narrow, obscuring the eardrum. B : The left external auditory canal and tympanic membrane are intact.

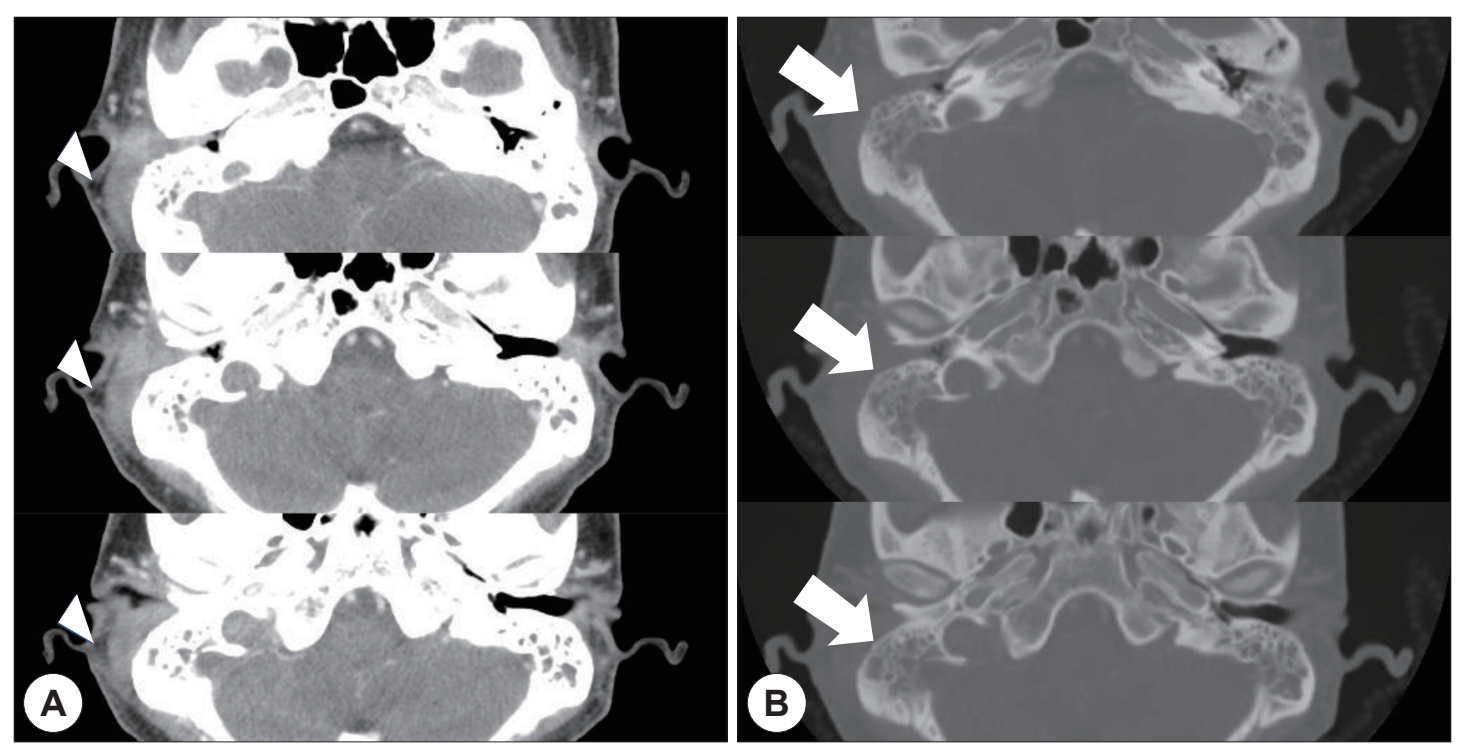

Fig. 2. Computed tomography images. A : Computed tomography shows opacification, although the structures in the mastoid antrum and mastoid air cells were relatively intact on both sides. A well-demarcated, homogenously enhanced dense soft-tissue mass was present in the right postauricular area (arrow heads). B : The right cortical bone near the auditory canal was partially eroded (arrow). 
canal and mastoid and the partial erosion of the cortical bone (Fig. 3). The mass appeared to be isointense with brain parenchyma on T1-weighted images and hyperintense with centrally located hypointense foci on T2-weighted images. On T1-weighted contrast-enhanced images, contiguous enhancement of the lesion was noted in the posterior regions of the middle and posterior fossa as well as in the geniculate ganglion.

Owing to swelling and redness in the postauricular area and overall narrowing of the external auditory canal without any granulation tissue, the patient was initially diagnosed with otomastoiditis with retroauricular abscess of the highest priority. Operative debridement and mastoidectomy were planned ; however, before starting the treatment, a deep site in the external auditory canal was biopsied to exclude the possibility of malignancy. The biopsy results confirmed the presence of a granulocytic sarcoma (Fig. 4).
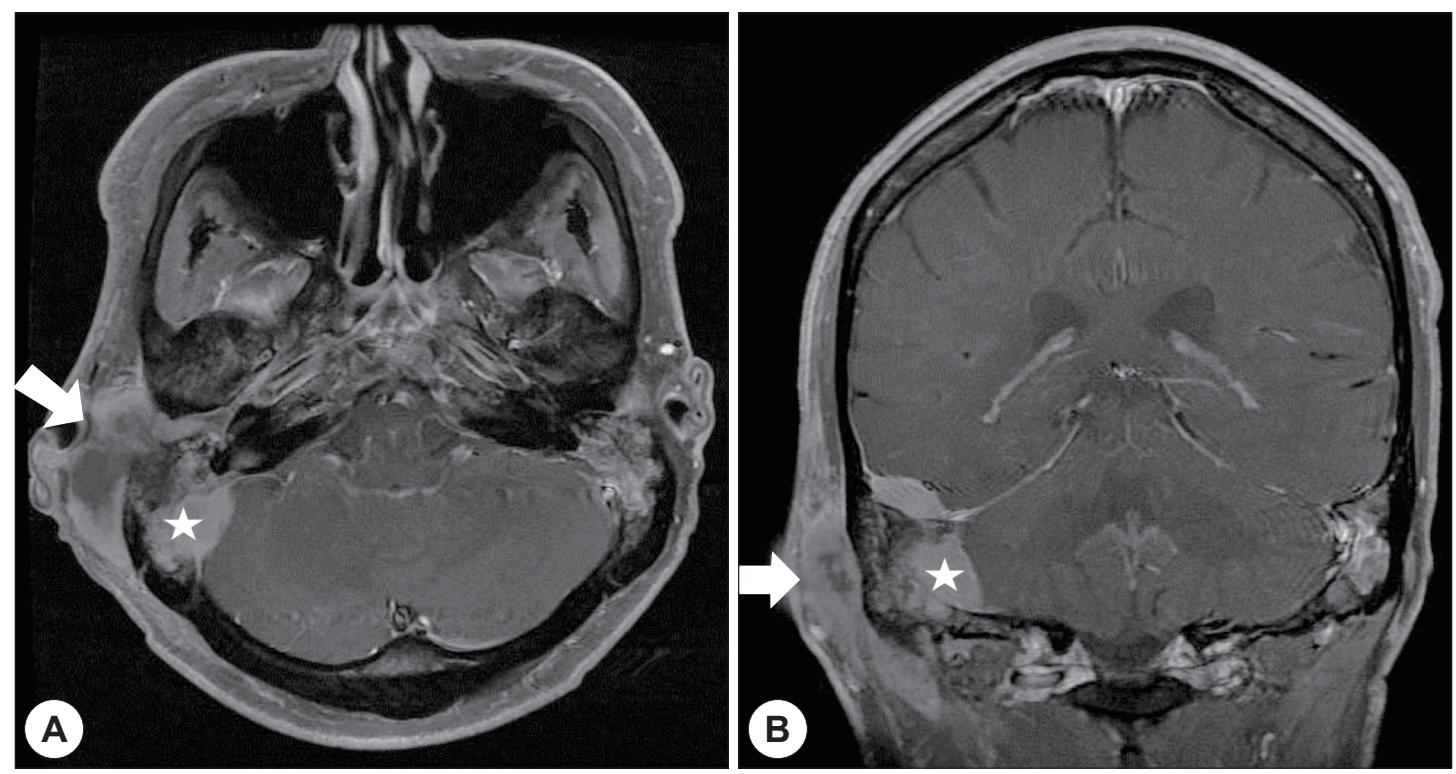

Fig. 3. T1-weighted magnetic resonance images with gadolinium. A, B : Axial and coronal images reveal a relatively homogenous enhanced mass with central hypointensity in the retro auricular area that extended to the external auditory tract and mastoid (arrow). Partial erosion of the cortical bone was also observed. Contiguous enhancement of the lesion was noted in the posterior regions of the middle and posterior fossa as well as in the geniculate ganglion (asterisk).
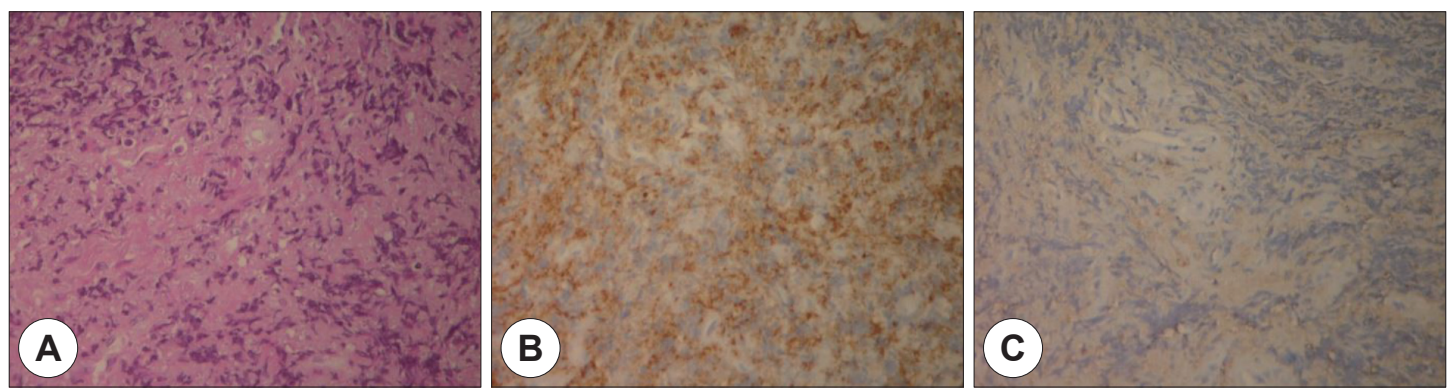

Fig. 4. Histology of the granulocytic sarcoma in the ear. A : Histologic evaluation of the dense fibrous tissue with cellular infiltration shows a preponderance of medium-sized cells with slightly irregularly shaped nuclei and scant cytoplasm. The admixed eosinophils had monolobated nuclei (hematoxylin and eosin staining; $\times 400$ ). B : Immunohistochemistry shows CD45 positivity in the neoplastic infiltrate $(\times 400)$. C : Immunohistochemistry shows diffuse staining of myeloperoxidase $(\mathrm{MPO})$ in the neoplastic infiltrate $(\times 400)$. 


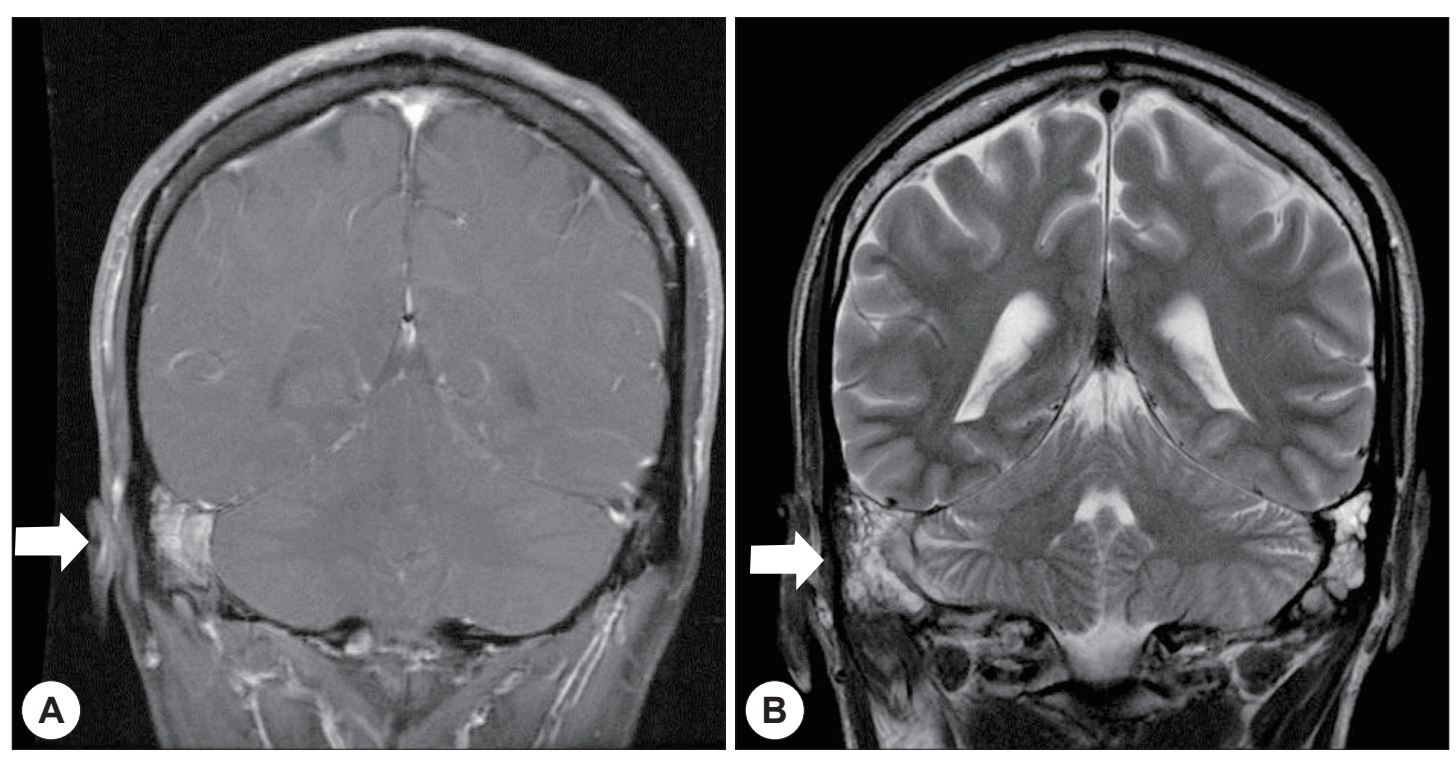

Fig. 5. Magnetic resonance imaging (MRI) 4 months after radiotherapy. A : Tl-weighted MRI with gadolinium shows resolution of the mass (arrow) and improved extension of the mid and posterior cranial fossa. B : T2-weighted MRI reveals fluid accumulation in both mastoid areas but no mass lesion in the retroauricular area, posterior regions of the middle and posterior fossa, or the geniculate ganglion (arrow).

Because the patient had severe pancytopenia owing to 3 previous cycles of chemotherapy, he underwent radiation therapy (cumulative dose, $30 \mathrm{~Gy}$ ). Examination of the ear discharge revealed the presence of methicillin-sensitive, coagulase-negative Staphylococcus, and the erythrocyte sedimentation rate and C-reactive protein level were mildly elevated. Moreover, CT of both mastoid bones suggested combined otomastoiditis. Hence, the patient received antibiotics in addition to radiotherapy.

Four months after radiotherapy and antibiotic administration, brain MRI showed no definite evidence of a remnant lesion excepting mastoiditis (Fig. 5). Furthermore, the facial palsy had partially improved (HouseBrackmann grade 2/6).

\section{Discussion}

Myeloid sarcoma, also known as chloroma, is a rare extramedullary collection of myeloid precursor cells. The term of chloroma is derived from the greenish color of the tumor, which is because of the presence of in- tracellular myeloperoxidase. ${ }^{2,7)}$ About $3 \%$ to $8 \%$ of all patients with acute myelogenous leukemia (e.g., acute and chronic myelogenous leukemia, polycythemia vera, and myeloid metaplasia) particularly those with the M2 subtype, have myeloid sarcoma. ${ }^{2,8)}$ Accurate diagnosis of myeloid sarcoma in leukemia patients is critical for effective therapy. The aggregation of immature myelogenous cells may indicate relapse or progression to blastic crisis. ${ }^{2,7)}$ Thus, a better clinical prognosis is required for early diagnosis and timely treatment of myeloid sarcoma patients.

Differentiating between myeloid sarcoma and otologic infection is challenging : the symptoms of myeloid sarcoma mimic those of otomastoiditis, and leukemia patients are highly susceptible to bacterial, viral, and fungal infections. ${ }^{9)}$ Imaging tests have proven useful in differentiating and delineating the extent of myeloid sarcoma. Noh et al. ${ }^{10)}$ reported the radiologic features of myeloid sarcoma based on their observations in 11 patients ; on CT and MRI, myeloid sarcomas are well-demarcated, homogenously enhanced masses with accompanying bone erosion at adjacent sites. In 
another study of myeloid sarcoma, MRI of the bone marrow revealed similar enhancement of signal intensity on T1- and T2-weighted images. ${ }^{11)}$ However, imaging features are not sufficient for distinguishing among lymphoma, meningioma, and pseudotumors because they are similar in all 3 conditions. ${ }^{12)}$ Biopsy is considered to be the best diagnostic tool ; however, its use may be considered unethical owing to the location of the sarcoma and the risk of comorbidities such as thrombocytopenia. ${ }^{13)}$ In the patient in our case, severe thrombocytopenia caused repetitive active bleeding at the biopsy. Biopsy should be performed at a deep site in the external auditory canal or on the right site of the mass lesion. Otherwise, the results will not provide enough information for a diagnosis different from inflammation.

There is no standard protocol for treating myeloid sarcoma ; however, early and aggressive treatment is essential to improve patient outcomes. ${ }^{14,15)}$ Prompt administration of systemic chemotherapy with occasional radiotherapy is required to prolong the survival of myeloid sarcoma patients and delay the relapse of leukemia. ${ }^{13,15)}$ In our case, the patient's condition improved after intensive radiotherapy although he underwent radiation therapy alone owing to severe pancytopenia. However, the prognosis of most myeloid sarcoma patients remains unfavorable even after massive administration of chemotherapy or radiotherapy. ${ }^{16)}$ Murakami et al. ${ }^{16)}$ reported that most myeloid sarcoma patients are at a risk of recurrence within 3 years. In the study by Pileri et al., ${ }^{14)} 60(89.5 \%)$ of the 67 myeloid sarcoma patients for whom follow-up data were available died off this disease. The mean survival time for myeloid sarcoma patients ranges between 2.5 and 22 months. ${ }^{2,5,17,18)}$

Myeloid sarcoma is not common in the head and neck region, and reports of sarcomas of the temporal bone are rare. Furthermore, its accurate diagnosis is difficult because its manifestations and imaging features resemble those of otomastoiditis. Timely diagnosis can majorly affect the clinical course of patients with myeloid sarcoma. Thus, otolaryngologists should conduct appropriate diagnostic evaluations of patients suspected of this disease.

\section{Conclusion}

Myeloid sarcoma is a rare extramedullary collection of myeloid precursor cells that is very difficult to differentiate from otologic infection. Combined histologic examination and imaging (e.g., CT and MRI) are necessary to facilitate early diagnosis of this disease, thus enabling the initiation of appropriate treatment.

\section{REFERENCES}

1) Lee B, Fatterpekar GM, Kim W, Som PM. Granulocytic sarcoma of the temporal bone. AJNR Am J Neuroradiol 2002;23(9):1497-9.

2) Neiman RS, Barcos M, Berard C, Bonner H, Mann R, Rydell RE, et al. Granulocytic sarcoma: a clinicopathologic study of 61 biopsied cases. Cancer 1981;48(6):1426-37.

3) Papamanthos MK, Kolokotronis AE, Skulakis HE, Fericean AM, Zorba MT, Matiakis AT. Acute myeloid leukaemia diagnosed by intra-oral myeloid sarcoma. A case report. Head Neck Pathol 2010;4(2):132-5.

4) Almadori G, Del Ninno M, Cadoni G, Di Mario A, Ottaviani F. Facial nerve paralysis in acute otomastoiditis as presenting symptom of FAB M2, T\&21 leukemic relapse. Case report and review of the literature. Int J Pediatr Otorhinolaryngol 1996;36(1):45-52.

5) Imrie KR, Kovacs MJ, Selby D, Lipton J, Patternson BJ, Pantalony D, et al. Isolated chloroma: the effect of early antileukemic therapy. Ann Intern Med 1995;123(5):351-3.

6) Szomor A, Passweg JR, Tichelli A, Hoffmann T, Speck B, Gratwohl A. Myeloid leukemia and myelodysplastic syndrome relapsing as granulocytic sarcoma (chloroma) after allogeneic bone marrow transplantation. Ann Hematol 1997; 75(5-6):239-41.

7) Binder C, Tiemann M, Haase D, Humpe A, Kneba M. Isolated meningeal chloroma (granulocytic sarcoma): a case report and review of the literature. Ann Hematol 2000;79(8): 459-62.

8) Cho JS, Kim EE, Ro JH, Pinkel DP, Goepfert H. Mandibular chloroma demonstrated by magnetic resonance imaging. Head Neck 1990;12(6):507-11.

9) Andres E, Kurtz JE, Maloisel F, Dufour P. Otological manifestations of acute leukemia: report of two cases and review of literature. Clin Lab Haematol 2001;23(1):57-60.

10) Noh BW, Park SW, Chun JE, Kim JH, Kim HJ, Lim MK. Granulocytic sarcoma in the head and neck: CT and MR imaging findings. Clin Exp Otorhinolaryngol 2009;2(2):6671.

11) Kransdorf MJ, Jelinek JS, Moser RP Jr. Imaging of soft tis- 
sue tumors. Radiol Clin North Am 1993;31(2):359-72.

12) Vinters HV, Gilbert JJ. Multifocal chloromas of the brain. Surg Neurol 1982;17(1):47-51.

13) Chang KH, Kim DK, Jun BC, Park YS. Temporal bone myeloid sarcoma. Clin Exp Otorhinolaryngol 2009;2(4):198202.

14) Pileri SA, Ascani S, Cox MC, Campidelli C, Bacci F, Piccioli M, et al. Myeloid sarcoma: clinico-pathologic, phenotypic and cytogenic analysis of 92 adult patients. Leukemia 2007;21(2):340-50.

15) Paydas S, Zorludemir S, Ergin M. Granulocytic sarcoma: 32 cases and review of the literature. Leuk Lymphoma. 2006;47
(12):2527-41.

16) Murakami M, Uno T, Nakaguchi H, Yamada SM, Hoya K, Yamazaki K, et al. Isolated recurrence of intracranial and temporal bone myeloid sarcomaYcase report. Neurol Med Chir (Tokyo) 2011;51(12):850-4.

17) Bassichis B, McClay J, Wiatrak B. Chloroma of the masseter muscle. Int J Pediatr Otorhinolaryngol 2000;53(1):57-61.

18) Szomor A, Passweg JR, Tichelli A, Hoffmann T, Speck B, Gratwohl A. Myeloid leukemia and myelodysplastic syndrome relapsing as granulocytic sarcoma (chloroma) after allogeneic bone marrow transplantation. Ann Hematol 1997; 75(5-6):239-41. 